\title{
Manifestações expressivas na inclusão digital: Ações integradas entre as artes e a informática na Educação de Jovens e Adultos
}

\author{
Clevi Elena Rapkewicz, Lisinei Rodrigues, Laura Bauermann \\ Colégio de Aplicação - UFRGS \\ clevi@ufrgs.br, lisinei@cap.ufrgs.br, laubauermann@gmail.com
}

Resumo: A Educação de Jovens e Adultos (EJA), no contexto do Colégio de Aplicação da UFRGS permite ao estudante vivenciar experiências pedagógicas que investem na inclusão digital e na docência compartilhada. Nessa perspectiva, este artigo analisa ações integradas entre Informática, e os conteúdos do componente curricular de expressão e movimento (Teatro, Música, Artes Visuais e Educação Física). Foi possível evidenciar que a inclusão digital pode ampliar-se de forma lúdica ressignificando a experiência de aprender.

Palavras-chave: artes, informática, EJA, inclusão digital.

Abstract: In the context of the Application College of the UFRGS (Federal University of Rio Grande do Sul), The Education of Youth and Adults (EJA) allows students to experience teaching practices based on digital inclusion and on shared teaching. In this perspective, this article analyzes some integrated actions between IT and the curriculum component contents of expression and movement (Theatre, Music, Visual Arts and Physical Education). The results showed that digital inclusion may widen in a playful way, redefining the experience of learning.

Keywords: arts, informatic, adult education, digital inclusion.

\section{1 - Introdução}

Este estudo foi desenvolvido em meio à ações propostas para a Educação de Jovens e Adultos (EJA) do Colégio de Aplicação da UFRGS (CAP/UFRGS) dentro do componente curricular de Expressão e Movimento. Nas áreas do conhecimento de Teatro, Artes Visuais, Educação Física, Música e Informática as atividades tiveram a abordagem do corpo como foco de estudo. A partir das perspectivas das diferentes áreas do conhecimento foram trazidas pela informática as ferramentas que funcionaram como meio para o acesso e o registro das ações práticas realizadas, além de incluir os alunos no universo digital. Nesse contexto, este artigo tem como objetivo permitir a discussão e a reflexão das possibilidades tecnológicas encontradas para abordar os estudos de expressão e movimento dentro do contexto da EJA na escola citada..

Para tanto, buscamos referências sobre as temáticas da inclusão digital e das práticas artísticas aliadas aos estudos da corporeidade na educação de jovens e adultos. 
Ao longo do trabalho, relatamos as ferramentas utilizadas como a nuvem de palavras, os infográficos, o tour virtual a teatros, os avatares, entre outros. Reconhecemos nessas ferramentas intenções de qualificar a experimentação, a prática corporal, e, por isso, consideramos que foram elementos que despertaram o interesse dos alunos e contribuíram para a inclusão digital. A utilização dos recursos visuais e sonoros proporcionados pela informática oportunizou a transposição de obstáculos tais como a visitação de salas de espetáculos em países distantes ou a frequência a concertos, espetáculos de dança e de teatro.

Esse trabalho justifica-se ainda, por divulgar ações que provêm do universo acadêmico (docentes) que dialoga diretamente com a comunidade (os alunos). $\mathrm{O}$ artigo evidencia o caráter interdisciplinar que constitui a experiência, uma vez que o foco são características do corpo sob a ótica de disciplinas curriculares concretizado com a ajuda de ferramentas tecnológicas. Ainda, a elaboração do texto leva-nos também a refletir sobre a educação que está se desenvolvendo no nosso contexto profissional, permitindo mudanças.

Nesse contexto, o artigo está organizado da seguinte forma: na seção 2 é abordado o referencial teórico a partir qual foram estabelecidos os pilares das ações feitas. Na seção 3 é apresentada a metodologia e na seção 4 é apresentado o relato e a análise das intervenções feitas integrando elementos do componente curricular de Expressão e Movimento com a Informática para, finalmente, apresentar na seção 5 algumas considerações finais.

\section{2 - Referencial teórico}

\section{2 .1 Inclusão digital: o aluno como prosumidor}

No papel relevante que a informação exerce atualmente, a informática e a WEB inserem novos conceitos que, avaliando a capacidade do ser humano de interagir com as novas TIC, a elas se integrando, consolidam também a emergência de um novo paradigma. Sob esse ponto de vista, Tapscott e Williams (2007) reconhecem que os consumidores também são produtores, ou seja, eles são prosumidores. O que este termo quer dizer? $\mathrm{O}$ conceito de prosumidor é de relevante importância, uma vez que é aceito na produção e no consumo de conhecimentos e aprendizagens. Cumpre registrar que estas potencialidades nasceram da área jornalística, ou seja, da comunicação, onde características automatizadas asseguradas e combinadas com técnicas amadoras incrementaram produções e deram maior acessibilidade e sucesso a estruturas de produções. O termo prosumidor descreve o fenômeno no qual se constata que o indivíduo não é apenas consumidor de conteúdos, é, ao mesmo tempo, produtor de informação. Parece conflitante o fato de ser produtor e consumidor ao mesmo tempo, mas é possível romper fronteiras e regras convencionais e participar de projetos de criação e produção de forma ativa e colaborativa. Essa expressão, que foi cunhada por Alvin Tofler (2007) em seu livro "A Terceira Onda", encontrou uma nova versão no mundo on-line. Trata-se do consumidor que possui mais poder, que emite opiniões, que produz informações sobre o que consome e influencia outros consumidores. 
Então, em tempos de internet, as mídias possuem uma fórmula cada vez mais alucinante de permitir que o indivíduo habituado a ser receptor da informação, passe também a ser autor, pois possui a capacidade de fornecer informações sobre o que se quer e como quer, ou seja, o prosumidor potencializa a aprendizagem e a colaboração.

A escola deve ser um espaço propício para que este fenômeno se dê de maneira eficaz. É papel da escola promover, entre os estudantes, um envolvimento interativo para produzir e consumir conteúdos, construindo desafios e procurando soluções de problemas. Mas é importante que os alunos não apenas se envolvam na solução de problemas elaborados pelo professor, mas que eles próprios sejam produtores de seu próprio conteúdo, garantindo assim que o fazer pedagógico se enquadre nas possibilidades cognitivas e despertem o interesse do educando. Mais do que produzir problemas, o professor precisa mediar ações, "ensejar e urdir múltiplos recursos" (SILVA, 2002).

No caso das ações integradas no eixo Expressão e Movimento do CAP/UFRGS, é essencial que os alunos possam construir seus próprios caminhos de conhecimento, ensejando suas próprias criações no escopo do Teatro, das Artes Visuais, da Música e da Educação Física. Os planos de ensino enfatizam o caráter experimental para o ato criativo porque no contexto da escola não se buscam produções artísticas em si, e sim formas de desenvolver a capacidade de expressão dos alunos nessas diferentes modalidades de representações do corpo. Busca-se, pois, o aluno prosumidor de artefatos culturais no âmbito dessas áreas, mediado pelas tecnologias, particularmente a informática.

Para o autor Warschauer (2006) o problema atual na abordagem da exclusão digital encontra-se no fato que se imagina que os contextos tecnológico e social podem se separar um do outro. Acredita-se, ingenuamente, que os programas idealizados para solucionar o problema tecnológico melhorarão um ou mais problemas sociais. Porém, conforme o autor, nenhuma tecnologia existe fora de uma estrutura social. Os domínios, tecnológico e social, estão muito entrelaçados e co-existem dentro das organizações, das instituições e da sociedade em geral, fazendo parte delas (BUNGE, 1995). Para Warschauer (2006), é necessário olhar para o que as pessoas fazem, suas práticas culturais, em lugar de centrar-se simplesmente na inovação tecnológica como fator de mudança.

No caso do CAP/UFRGS, as práticas artísticas e a relação com o corpo, através da mediação da tecnologia, constituíram o ponto de partida para as intervenções pedagógicas analisadas.

\section{2 - Expressão e movimento na Educação de Jovens e Adultos}

O público da EJA no CAP/UFRGS constitui-se de forma diversificada quanto a sua faixa etária e quanto aos seus interesses dentro de sala de aula. Segundo o plano de ensino do departamento de Expressão e Movimento (da mesma instituição), o trabalho com a EJA busca "[...] a capacidade de exercer um olhar crítico sobre as manifestações das sociedades e sobre nós mesmos enquanto agentes dessas manifestações." Sob essa perspectiva buscamos olhar para esses agentes através da sua identidade e da cultura na 
qual estão inseridos, entendendo-os como personalidades que ocupam um lugar único em sala de aula, caracterizados por suas ações e relações dentro de cada contexto..

Para tanto, é necessário pensar o aluno na sua totalidade, conforme João Bernardes Rocha Filho (2007), e valorizar na proposta de ensino as suas memórias e suas ideias, despertando seu gosto pelo pensar. E assim, ao estabelecer um campo confiável para a criação durante as aulas, possibilitar o desenvolvimento da autonomia de quem está pensando e produzindo arte, educação e seus aspectos culturais.

Rocha Filho (2007) coloca ainda que a escola, a fim de dar conta da realidade contemporânea, deve promover o desenvolvimento no sentido de capacitar os alunos a pensar de forma criativa e ética, e de agir segundo esse pensar. Percebemos aqui, um indicativo importante de espaço para arte e criação dentro das instituições de ensino.

Ainda, ao considerar a cena atual cada vez mais abarrotada de informações, Roberto Crema (2003) sugere que a escola deva trabalhar no sentido de facilitar a compreensão de si e do mundo em transformação contínua, enfatizando tanto a intuição e o sentimento, quanto a razão e a sensação, cultivando dentro do ambiente escolar os valores da humanidade. Nessa última referência, encontramos a oportunidade de aproximar o corpo e suas representações, cotidianas ou não, como objeto de estudo, proporcionando ao estudante um espaço de apropriação de elementos artísticos e culturais..

Gabrielle Roth, em Os Ritmos da Alma (1997, p.26) escreveu que "A energia move-se em ondas. Ondas movem-se em padrões. Padrões movem-se em ritmos. Um ser humano é apenas isso, energia, ondas, padrões, ritmo. Nada mais. Nada menos. Uma dança." $\mathrm{O}$ ato de destacar características encontradas nas artes e no movimento (ou seja, fazer uso da energia, da onda, dos padrões e do ritmo como fonte de inspiração), integra a produção de gestos e as concepções de corpo, abre espaço para que a movimentação corporal e as criações sejam permeadas por sensações e qualidades oriundas do contexto, da musica, e de outras percepções.

Gabrielle Roth, em Os Ritmos da Alma (1997, p.26) escreveu que "A energia move-se em ondas. Ondas movem-se em padrões. Padrões movem-se em ritmos. Um ser humano é apenas isso, energia, ondas, padrões, ritmo. Nada mais. Nada menos. Uma dança." O ato de destacar características encontradas nas artes e no movimento (ou seja, fazer uso da energia, da onda, dos padrões e do ritmo como fonte de inspiração), integra a produção de gestos e as concepções de corpo, abre espaço para que a movimentação corporal e as criações sejam permeadas por sensações e qualidades oriundas do contexto, da música, e de outras percepções.

Assim, trabalhar com expressão e movimento destacando os contextos culturais e trazendo as memórias e conhecimentos dos alunos, prevê ampliar o foco do estudo, considerando diversos elementos que constituem as artes e o corpo em evidência, explorando seus conteúdos simbólicos; concordando com a autora Mariana Monteiro (2011, p.45) quando afirma que "A vida cultural é sempre uma forma poderosa de manipulação do real por meio do símbolo, cuja eficácia reforça um campo relativamente autônomo de significados". 
Acreditamos, na potência das ações desse componente curricular para os estudantes da EJA do CAP/UFRGS, pois atividades como os jogos teatrais, o aprendizado de um canto, a produção de um retrato com uma abordagem consciente e responsável das possibilidades do corpo, colocam o cotidiano sob o foco das discussões em aula. Olhar para a própria identidade e perceber-se como agente de sua cultura, pode contribuir para a formação de um olhar crítico sobre si e a sociedade. Essas propostas agiram promovendo o interesse dos alunos, permitindo que cada um trouxesse questionamentos, prioridades para o ambiente escolar e aproximações da escola com a vida profissional e familiar de cada um.

Segundo Flávio Desgranges (2010, p. 28), o ato de contemplar a arte é que torna possível a elaboração de sentidos para a mesma.

O acontecimento artístico se completa quando o contemplador elabora a sua compreensão da obra. A totalidade do fato artístico, portanto, inclui a criação do contemplador. Na relação dos três elementos - autor, contemplador e obra - reside o evento estético. O fato artístico não está contido no objeto, nem no psiquismo do criador, nem do receptor, mas na relação destes três elementos.

Algumas das ações objetivaram experimentar as diversas formas de representação que nos deparamos na ficção e na realidade. Por exemplo, ao assistir a uma obra teatral, temos consciência de que há a contemplação de um universo ficcional. Apesar de haver a presença física dos atores em cena, os fatos, mesmo quando baseados na realidade, constituem a representação de algo.

Sobre a noção de presença cênica do ator teatral e suas interações com os aparatos tecnológicos no teatro contemporâneo, Béatrice Picon-Vallin (2005, p.74) explica que:

\begin{abstract}
Atualmente, a cena é este lugar único onde estão postos o espectador e o ator diante de múltiplas imagens-representações que os circundam na vida quotidiana, de toda palheta de seus duplos tecnológicos, fotográficos, fílmicos, videográficos, clones virtuais ou marionetes eletrônicas. Ela é, sem dúvida, hoje, um dos raros espaços, ao mesmo tempo, experimentais e lúdicos onde se pensa as mutações tecnológicas em presença dos corpos vivos, aqueles dos atores e dos espectadores. Ela fomenta interrogações sobre o conceito de presença e sobre a maneira de criá-la, modificá-la, intensificá-la, pois a imagem ao vivo ou pré-gravada de um ator é freqüentemente mais fascinante do que o ator sobre a cena, porque é infinitamente modificável e móvel.
\end{abstract}

Nas propostas pedagógicas da EJA havia a possibilidade de trabalhar tanto com o ator e o espectador em situações ficcionais, presenciais e efêmeras, no que poderíamos chamar de "teatro tradicional", quanto com a contextualização da cena contemporânea que borra as fronteiras entre as diferentes modalidades artísticas e avança em direção ao que o grupo de docentes passou a denominar "cultura digital".

A problematização das noções do que seria verdadeiro ou falsificado (ou representado) na Internet, por exemplo quando se deparam com perfis nas redes sociais, passou a ocupar as intenções pedagógicas. Partindo dessa prática, pensar sobre a criação de perfis e representações individuais para nos comunicarmos com os outros usuários, 
tentando identificar quando o perfil é uma reprodução da realidade e quando é uma representação.

\section{3 -Metodologia}

Nesta seção apresentamos os sujeitos da pesquisa e os "procedimentos", por assim dizer, utilizados, com seus respectivos materiais. A metodologia usada foi a pesquisa-ação. A pesquisa-ação, método qualitativo particular de pesquisa social, enfatiza especificidades, onde o pesquisador detecta um problema em seu meio, buscando estratégias de ação para modificar a situação identificada. Favorece as discussões e a produção cooperativa de conhecimentos específicos sobre a realidade vivida, com foco principal na análise das práticas instituídas no convívio social. Para Thiollent (2007) pesquisa-ação é:

[...] um tipo de pesquisa social com base empírica que é concebida e realizada em estreita associação com uma ação ou com a resolução de um problema coletivo e no qual os pesquisadores e os participantes representativos da situação ou do problema estão envolvidos de modo cooperativo ou participativo. (THIOLLENT, 2007, p. 16).

Atualmente muito aplicada na área da educação, a pesquisa-ação serve para elaborar uma análise de uma realidade em que o pesquisador está envolvido, unindo a ação à prática. Analisa-se uma dada situação e, a partir dela, busca-se resolver um problema. No contexto deste estudo, o problema coletivo a ser resolvido foi a melhora do nível de inclusão digital de alunos de Ensino Médio na modalidade EJA no CAP/UFRGS através de manifestações culturais e artísticas relacionadas aos componentes curriculares do eixo Expressão e Movimento.

Os sujeitos da pesquisa foram, portanto, o conjunto de alunos do nível médio, modalidade EJA na escola citada. Foram cerca de 60 alunos de três turmas correspondentes ao $1^{\circ}, 2^{\circ}$ e $3^{\circ}$ ano do Ensino Médio, ainda que muitos não frequentem regularmente as aulas (o que, aliás, provocou certa ruptura nas atividades). A amplitude etária é grande, com alunos entre 18 e 66 anos de idade.

A primeira etapa da pesquisa foi o levantamento quantitativo através de um questionário quanto ao nível de inclusão digital dos alunos. Foi perguntado aos alunos qual o grau de familiaridade dos mesmos com cerca de 40 competências em microinformática que variam de questões simples como ligar computador, usar mouse, etc até mais amplas relacionadas a ferramentas que permitem formas de expressão (criação de blog, edição de áudio, etc). A partir do diagnóstico, foi analisado o potencial para autoria dos mesmos e proposta uma série de intervenções durante um ano. Na impossibilidade de tratar de todas elas no escopo deste artigo, apresentamos, no quadro a seguir, alguns instrumentos e procedimentos utilizados. $\mathrm{O}$ conjunto de atividades feitos está registrado em aplicacaoeja.pbworks.com 
Quadro 1 - Intervenções e procedimentos feitos na EJA da escola X

\begin{tabular}{|c|c|c|}
\hline Atividade & Instrumento & Procedimentos \\
\hline Avatares & Voki & $\begin{array}{l}\text { Os alunos assistiram um vídeo disponível em } \\
\text { http://vimeo.com/62470169. Logo depois houve a discussão do vídeo e } \\
\text { então cada aluno recriou um personagem (incluindo o tablet e o próprio } \\
\text { público) posicionando-se criticamente em relação à situação exposta no } \\
\text { vídeo. }\end{array}$ \\
\hline $\begin{array}{c}\text { Fotos } \\
\text { antigas }\end{array}$ & SumoPaint & $\begin{array}{l}\text { Primeiramente, foi trabalhado na aula de teatro, intenção, postura e } \\
\text { atitude frente à poses para fotografias antigas. Depois, foram tiradas } \\
\text { fotos com estas posturas no teatro da escola. Na sequência, os alunos } \\
\text { pesquisaram na Web fotos antigas de cenários. Finalmente, os alunos } \\
\text { foram ao laboratório de informática envelhecer as fotos tiradas no teatro } \\
\text { da escola e inserir as mesmas nos cenários pesquisados através de } \\
\text { edição de imagens. }\end{array}$ \\
\hline Infográficos & Prezi & $\begin{array}{l}\text { No primeiro momento, os alunos escolheram temáticas acerca de } \\
\text { manifestações artísticas expressivas. Então, buscaram na web informações } \\
\text { para construir os infográficos, alguns alunos utilizaram imagens também } \\
\text { retiradas da web, outros produziram fotos. Construíram infográficos } \\
\text { sobre as expressões artísticas escolhidas e apresentaram para os colegas, } \\
\text { usando o infográfico como instrumento para a apresentação. }\end{array}$ \\
\hline $\begin{array}{l}\text { Tour a } \\
\text { museus }\end{array}$ & Tour virtual & $\begin{array}{l}\text { Nesta atividade, os estudantes visitaram teatros nacionais e } \\
\text { internacionais por meio da ferramenta de tour virtual que muitos teatros } \\
\text { disponibilizam no próprio site. Para facilitar a atividade, foi construída } \\
\text { uma lista numa Wiki, com vários teatros que ofertam essa possibilidade. } \\
\text { Cada aluno escolheu qual o espaço visitado que mais lhe interessou. Os } \\
\text { relatos foram recolhidos e a partir dos argumentos utilizamos a ferramenta } \\
\text { da nuvem de palavras (http://www.wordle.net) foi utilizada para } \\
\text { visualizar os aspectos que mais interessaram aos estudantes durante a } \\
\text { visita. A ação ainda se desdobrou em uma atividade integrada com outra } \\
\text { turma do EJA, na qual o grupo de alunos que visitou os teatros } \\
\text { apresentou-os para os colegas argumentando e discutindo temas em } \\
\text { relação à estrutura dos teatros. Ao final, a lista de teatros com tour } \\
\text { virtual disponível é ampliada através de pesquisa dos próprios alunos }\end{array}$ \\
\hline
\end{tabular}

\section{4 - Relato e análise das intervenções}

Dentro da gama de ações propostas de forma integrada entre mais de uma área do conhecimento, escolhemos quatro, para relatar e analisar a fim de ilustrar as atividades desenvolvidas e permitir reflexões sobre a prática.

A atividade desenvolvida com avatares se desenrolou a partir de um vídeo assistido em aula, o qual trouxe questões relacionadas ao intenso uso de tecnologia no cotidiano. Então, a proposta seguiu por uma discussão acerca do tema "tecnologia" guiada pela identificação dos personagens presentes no vídeo, bem como da postura de cada um frente ao tema. Nesse momento, surgiram dois novos personagens: os alunos consideram-se participantes da cena, enquanto plateia, mas também consideraram o tablet (objeto foco da discussão do vídeo) como um personagem. 
O próximo passo foi recriar os personagens: utilizando a ferramenta VOKI $<$ http://www.voki.com/>, os estudantes recriaram personagens e falas posicionando-se de forma crítica em relação à situação exposta no vídeo. Em seguida esses personagens foram encenados na aula de teatro. Assim, foi proporcionado aos alunos, reconhecer um tema atual, refletir e discutir sobre a questão e ainda expressar a sua posição, tanto utilizando a via corporal, como utilizando ferramentas disponíveis na web. Ainda, permitiu que os alunos deixassem a posição de espectador e experimentassem atuar como criadores da cena, interferindo no seu desfecho.

A segunda atividade destacada foi a elaboração de fotos antigas. $\mathrm{O}$ processo foi bem extenso no sentido de experiências vivenciadas, pois, foi preciso estudar primeiro as atitudes, posturas e intenções corporais desejadas para a foto; um trabalho de projetar uma imagem que será concretizada somente no final do produto. Depois de feitas as fotografias, os alunos buscaram os cenários desejados e então, as imagens foram editadas com o programa SUMO PAINT, disponível online em $<$ http://www.sumopaint.com/app/>. Depois de pronto, foi interessante analisar como se processou essa primeira intenção da foto que foi transformada pelo cenário e pela edição da imagem.

Outra ação proposta foi a construção de infográficos, por meio do Prezi <www.prezi.com>, uma ferramenta online que permite criar apresentações, os alunos realizaram o projeto, o qual consistia em pesquisar temas relativos a poéticas corporais e manifestações artísticas na web e posteriormente, construir informativos com fotos, textos e personagens. O diferencial desse editor é a possibilidade de utilizá-lo como um mapa disposto na web, tendo as informações disponíveis em um espaço livre, no qual pode-se ampliar o zoom para ver os detalhes e reduzir o zoom para ver a totalidade da apresentação. A atividade proporcionou aos estudantes o contato com recursos que podem ser utilizados por eles futuramente para realizar apresentações de outros trabalhos solicitados na EJA. Um fator importante a ser considerado foi também a temática parcialmente livre, em que os estudantes puderam optar e descobrir manifestações artísticas que lhes despertavam interesse, mas que haviam sido pouco exploradas por eles.

Por fim, trazemos o relato da atividade dos tours virtuais, na qual os alunos visitaram o interior de teatros do Brasil e do exterior. As visitas geraram muitos questionamentos e curiosidades em relação à arquitetura dos prédios, à estrutura dos palcos, entre outras. A partir desses interesses que foram surgindo, cada aluno escolheu um espaço visitado e argumentou a sua escolha. Os relatos foram recolhidos e a partir dos argumentos utilizamos a ferramenta da nuvem de palavras para visualizar os aspectos que mais interessaram aos estudantes durante a visita.

Em um segundo momento, a ação e desdobrou em uma atividade integrada com outra turma da EJA. O grupo que realizou as visitas apresentou os teatros que mais lhes chamaram a atenção para outros colegas. A interação entre estudantes proporciona uma experiência ímpar, na qual as dúvidas da plateia puderam ser respondidas pelos próprios colegas, tivemos neste momento uma oportunidade de experimentar a mistura entre apresentar e contemplar, entre ensino e aprendizagem. Das questões que se destacaram, 
temos: a presença das cores vermelha e dourada, predominantes na ornamentação dos teatros, a marcação do Fosso da Orquestra, as linhas curvas frequentes na arquitetura dos espaços e a implicação dessa arquitetura nas propriedades do som.

A partir do relato acima, percebemos como, facilmente, os recursos da informática atravessam as atividades do componente curricular de expressão e movimento. E recordando a característica diversificada do público da EJA, acreditamos que a integração de mais de uma área de conhecimento em uma mesma ação possam promover mais envolvimento dos estudantes à medida que uma mesma atividade engloba mais de uma habilidade.

Assim, ao aproximar as noções de presença e contemplação, abordadas nos jogos teatrais, com as possibilidades de criação por meio de identidades virtuais, que denominamos "avatares", foi possível proporcionar ao aluno a autoria de objetos de ficção. Ao tornar-se criador de uma obra e contemplador da mesma, o estudante pode completar de maneira crítica e consciente um evento estético.

Da mesma forma, percebemos na produção de fotografias o sentido de pertencimento citado anteriormente em outros processos artísticos. Isso ocorreu desde a caracterização do sujeito que serviu de personagem para a foto, através de figurinos e acessórios cênicos, passando pelo registro da imagem até o tratamento da mesma para o produto final. Criando a partir da primeira projeção de atitude corporal, uma cena completa com os recursos digitais de edição de imagem disponíveis na ocasião, foi possível que o estudante se transportasse para um tempo e espaço imaginados, recriados.

\section{5-Considerações finais}

A imersão dos estudantes em processos artísticos complexos, como a projeção de uma cena ou a recriação de um personagem, permitiu que eles valorizassem as manifestações artísticas. Partindo do princípio que a experimentação proporcionou ações de autoria, o reconhecimento de si como produtor de cultura e como contemplador de outras culturas, estabeleceu sentidos para as experimentações e a própria existência do componente curricular de Expressão e movimento no currículo da EJA, existência esta muitas vezes questionada em detrimento de maior carga horária de componentes curriculares mais conteudistas como Matemática, Química e outros.

No que se deve à atuação dos estudantes, ao analisar seus trabalhos, bem como o envolvimento com as ações propostas, percebemos que a inserção da arte e dos estudos sobre o corpo gera curiosidade e interesse dos mesmos. Essa motivação desloca o aluno da sua prática comum, e o lança para um ambiente de novidades, de descobertas em relação a si mesmo e ao grupo.

Portanto, proporcionar que os estudantes representem outra personalidade ou projetem suas atitudes para um contexto imaginado, gera ampliação da consciência corporal, e da percepção de como expressar e tornar comunicáveis as suas intenções. E assim, ao vivenciar formas de expressão e movimento distintas ser capaz de reconhecer também suas potencialidades enquanto artista e enquanto sujeito criador; e deste modo, 
agir de forma a improvisar frente aos desafios, fazendo uso dessa sabedoria atrelado às atitudes.

No que diz respeito ao papel dos alunos como prosumidores, note-se que o consumo de informações ocorre em praticamente todas as atividades. Este consumo tanto é feito de informações já localizadas pelos professores (como por exemplo, o vídeo mencionado na atividade com avatares e a lista de teatros com tour virtual) como através de pesquisa e seleção como no caso da escolha de cenários para edição das fotos e pelo acréscimo de teatros na lista pré-existente. A produção se dá através da criação de personagens através dos avatares e também através da edição de fotos, inserindo o aluno-personagem das fotografias antigas feitas no teatro da escola em cenários antigos escolhidos por eles. As manifestações de prazer dos alunos ao verem suas próprias criações e dos colegas mostra o quanto é importante aproveitar os diversos recursos de autoria disponíveis na Web 2.0 para desenvolver o aluno-autor, oportunizando um processo de inclusão digital através da integração da informática com os componentes curriculares de Expressão e Movimento.

\section{Referências}

CREMA, R.; WEIL, P.; LELOUP, J.Y. Normose - a Patologia da Normalidade. Campinas - SP: Versus Editora, (2003).

DESGRANGES, F. Pedagogia do teatro: provocação e dialogismo. São Paulo: Hucitec, 2010.

MONTEIRO, M. F. M. Dança popular: espetáculo e devoção. São Paulo: Terceiro Nome, (2011).

PICON-VALLIN, B. Os novos desafios da imagem e do som para o ator: em direção a um "super-ator"? Revista Cena. Vol. 7. Porto Alegre: IA/UFRGS, 2005

ROCHA FILHO, J. B.; BASSO, N. R. S.; BORGES, R. M. R. Transdisciplinaridade: a natureza íntima da educação científica. Porto Alegre: EDIPUCRS, 2007.

ROTH, Gabrielle. Os ritmos da alma: o movimento como prática espiritual. São Paulo: Cultrix, (1997).

SILVA, M. Sala de aula interativa. Rio de Janeiro: Quarter, (2002).

TAPSCOTT, D.; WILLIAMS, A. Wikinomics: como a colaboração em massa pode mudar o seu negócio. (Tradução de Marcello Lino). Rio de Janeiro: Nova Fronteira, (2007).

THIOlleNT, M. Metodologia da Pesquisa-Ação - 15. ed. São Paulo: Cortez, (2007). [Coleção Temas Básicos de Pesquisa-Ação]

TOFFLER, A. A terceira onda. Rio de Janeiro: Record, (2007).

WARSCHAUER, M. (2006) Tecnologia e Inclusão Social: a exclusão digital em debate. São Paulo: Editora SENAC São Paulo. 